\title{
Particle Crushing and Morphology Evolution of Saturated Crushed Gangue under Compaction
}

\author{
Bangyong Yu $\mathbb{D D}^{1,2}$ Shucai Pan $\mathbb{D}^{1},{ }^{1}$ and Kaisheng Xu $\mathbb{D}^{1}$ \\ ${ }^{1}$ Institute of Construction Engineering Technology, Changzhou Vocational Institute of Engineering, Changzhou 213164, \\ Jiangsu, China \\ ${ }^{2}$ State Key Laboratory for Geomechanics \& Deep Underground Engineering, China University of Mining \& Technology, \\ Xuzhou 221116, Jiangsu, China \\ Correspondence should be addressed to Shucai Pan; 8000000749@czie.edu.cn
}

Received 22 August 2020; Revised 24 September 2020; Accepted 28 October 2020; Published 12 November 2020

Academic Editor: Hualei Zhang

Copyright $\odot 2020$ Bangyong Yu et al. This is an open access article distributed under the Creative Commons Attribution License, which permits unrestricted use, distribution, and reproduction in any medium, provided the original work is properly cited.

\begin{abstract}
In this research, the deformation, particle crushing, and morphology evolution of saturated crushed gangue under variable axial stresses $(0,2,4,8,12,16$, and $20 \mathrm{MPa})$ were investigated by performing a series of laboratory tests with our self-designed compacting device. The research results showed that the relationship between compression modulus and axial stress can be expressed by an exponential function. The relative breakage varied from 0 to 0.3685 and increased monotonously with the increase of axial stress. The relation between relative breakage and axial strain was described by a linear function. The particle circularity varied from 1.179 to 1.361 and decreased gradually with the increase of axial stress. When the axial stress increased from $0 \mathrm{MPa}$ to $2 \mathrm{MPa}$, the relative breakage increased rapidly by over $39.15 \%$ of the total increase, and the particle circularity of large particles in the range of $15-20 \mathrm{~mm}$ sharply decreased by over $48.34 \%$ of the total decrease. $2 \mathrm{MPa}$ was a key value in controlling the particle crushing of the saturated crushed gangue during compaction. Particle crushing was predominantly divided into three types: fracture, crushing, and grinding. At the early stage of compaction, fracture and crushing took place in large numbers. At the end, grinding was the main form of particle crushing. The axial strain was influenced by the initial gradation, and a larger Talbot exponent corresponded to a larger strain. However, the initial gradation had little effect on the relative breakage.
\end{abstract}

\section{Introduction}

Crushed rocks are widely distributed in mining engineering [1]. Because of the high porosity of these rocks, large compressive deformation occurs in crushed rock mass in caved zones, which support the overlying strata. This influences the support of the roadway, the management of the roof, and the control of surface subsidence. Moreover, particle crushing leading to the evolution of grain size distribution during compaction is one of the internal factors (in addition to rock type, particle shape, degree of saturation, loading mode, etc.) required for determining the compaction properties of the crushed rocks. Therefore, the study of particle crushing and compaction properties of the crushed rocks has a crucial role in mining engineering. For example, it helps engineers predict and control the surface subsidence in coal mining process $[2,3]$.
In recent decades, many relevant studies have been conducted to investigate the particle crushing of granular materials [4-8]. The results have suggested that particle crushing, which may occur during compaction, is predominantly affected by the applied stress, the initial grading of the tested materials, the change in particle mixture, the geological framework, and the complex shape in physics and geometry. In this regard, the fractal theory has been employed to quantitatively describe the broken degree of the soil particles and rock particles [9-12]. When particle crushing takes place, the particle morphology will change as a result. Two- and three-dimensional evaluation methods have been proposed to quantify the morphology evolution of particles [13-17]. However, few studies have been carried out regarding the particle crushing and morphology evolution of the broken rock mass in caved zones. This research gap was an incentive to perform this study. 
Studies have been conducted broadly to investigate the compaction properties of crushed rocks [7, 18, 19]. The influences of particle size and strength on the deformation characteristics of saturated crushed rocks have been analyzed in this regard [20]. A series of laboratory tests have been also conducted to study the creep properties of crushed rocks [21, 22]. However, most of the studies have focused on the crushed rocks in a single particle size range and have ignored the relationship between the particle crushing and compaction properties.

Overall, the main objective of this study was to further enhance the understanding of the compaction properties in terms of particle crushing and particle morphology evolution. Furthermore, the quantitative study of particle crushing and morphology evolution was performed, and the quantitative relationship between the axial strain and relative breakage was obtained too. The results, which will be presented later in this paper, provided a scientific basis for the prediction and control of surface subsidence in coal mining engineering.

\section{Experimental System and Procedure}

2.1. Testing System. To observe the compression process of the specimen, a visual compacting device was designed. Figure 1 illustrates the components of this compacting device and also the design principle. This self-designed compacting device had four main parts: piston, steel cylinder tube, plastic cylinder tube, and pedestal. The piston was used to apply the axial load. The steel cylinder tube was made of fully quenched $45 \#$ steel. The inner diameter and the wall thickness of this steel cylinder were 120 and $8 \mathrm{~mm}$, respectively. The plastic cylinder tube was employed to observe the specimen. It was composed of polycarbonate material. The inner diameter and the wall thickness of this tube were 100 and $10 \mathrm{~mm}$, respectively.

2.2. Specimen Preparation. The gangue specimens used in this test were taken from Longxiang coal mine located in the Shandong province of China. The specimens were prepared in the laboratory according to the following procedure. The gangue block was initially crushed, and the particles were separated into several groups with diameter sizes ranging from 2 to $5,5-10,10-15$, and $15-20 \mathrm{~mm}$. This classification was performed using appropriate sieves. Considering that the gangue block in caved zones contained different sizes, the particle groups in each specimen constituted of a grain diameter that belonged to group a $(2-5 \mathrm{~mm})$, group $b$ (5-10 mm), group c (10-15 mm), and group d (15-20 mm), and the total mass was $1500 \mathrm{~g}$. In order to overcome the dimension disaster and reduce the number of tested specimens, the particles within different sizes were mixed based on Talbot theory [23]. The Talbot formula is written in the following form:

$$
P=\left(\frac{d}{D}\right)^{n} \times 100 \%
$$

where $P$ denotes the passing rate of each grain size in rock particles, $d$ signifies the grain diameter, $D$ stands for the maximum diameter, and $n$ indicates the Talbot exponent. Figure 2 shows the grain grading curves for four different cases $(n=0.2, n=0.4, n=0.6$ and $n=0.8)$. As seen in Figure 2, the mass amount of large particles increases with the increase of the Talbot exponent. Finally, the specimens were placed into a glass container filled with water for seven days to ensure that they were fully saturated.

2.3. Testing Procedure. As a result of the overlying strata movement, the crushed gangue particles in caved zones support different amounts of loading at different times. The resulting compression increases gradually due to the change in the ground stress. Therefore, the impact of the compression level (axial stress) was investigated in this study. Considering the strata depth $(-730 \mathrm{~m})$ and the in situ strata stress (an average bulk density of $0.024 \mathrm{MN} / \mathrm{m}^{3}$ ), the maximum axial stress of $20 \mathrm{MPa}$ was set for the compression test. The axial stress was set to six different levels $(2,4,8,12$, 16 , and $20 \mathrm{MPa}$ ). Thus, particle crushing and morphology evolution were tested under seven different conditions (including the initial state). Twenty-eight sets of experiments were conducted (four different initial gradations $\times$ seven different axial stresses). Each set of experiments was carried out three times, and the average values of the test data were used in the analysis. The test steps were as follows:

\section{(1) Installing the specimen:}

After assembling the compacting device, a new saturated specimen was placed into the compacting device. Then, the initial height of the specimen was calculated and recorded, and the compacting device was placed on the platform of the compression machine.

(2) Applying the axial pressure:

The control mode of the axial force was applied, and the loading rate was set to $0.2 \mathrm{kN} / \mathrm{s}$. After the axial pressure reached the required pressure, the compacting device was uninstalled.

(3) Testing the grain size distribution:

The gangue particles of each specimen were sieved. After drying the gangue particles, the mass in each size range was measured.

(4) Obtaining the particle morphology:

The pictures of the particles in different size ranges $(2-5,5-10,10-15$, and $15-20 \mathrm{~mm})$ were obtained using a digital camera. Also, the Image J software was employed to process the images.

(5) Changing the axial pressure:

The axial pressure was changed, and the steps (2)-(4) were repeated.

(6) Changing the new specimen:

During the compaction, the particle crushing and pore structure evolution were observed through the visual window of the compacting device. 


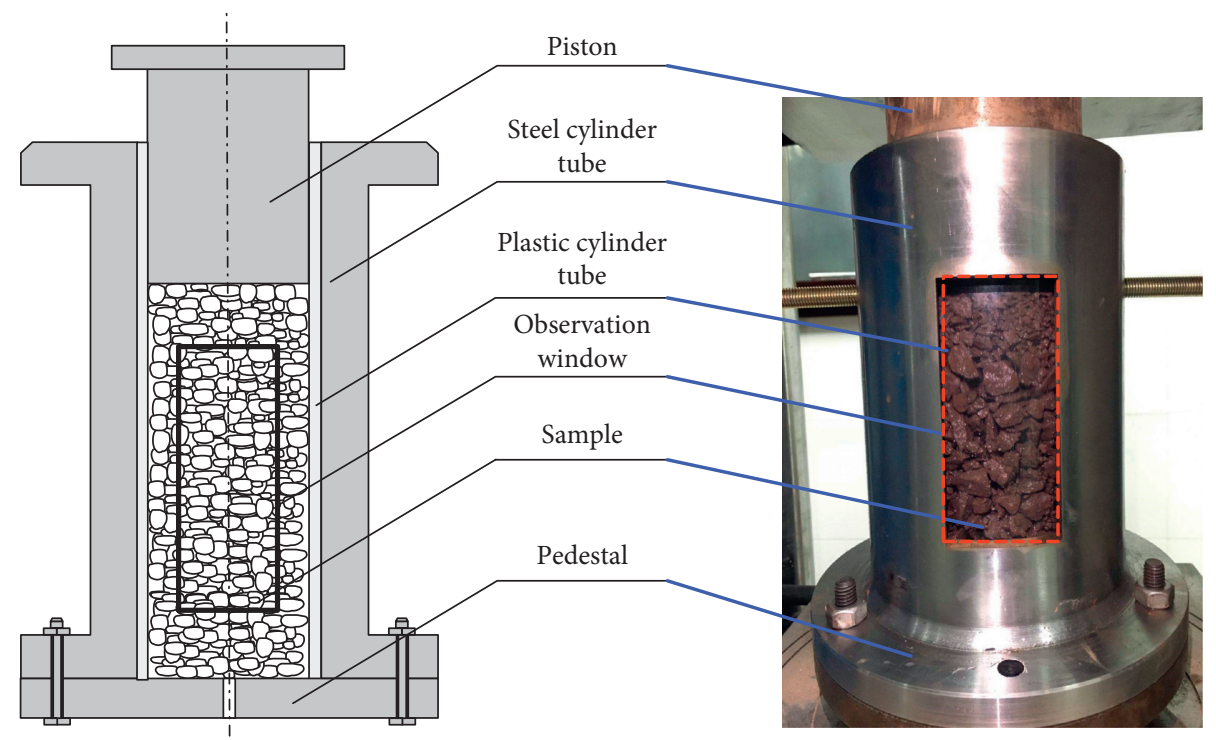

FIGURE 1: Self-designed compacting device employed in this research.

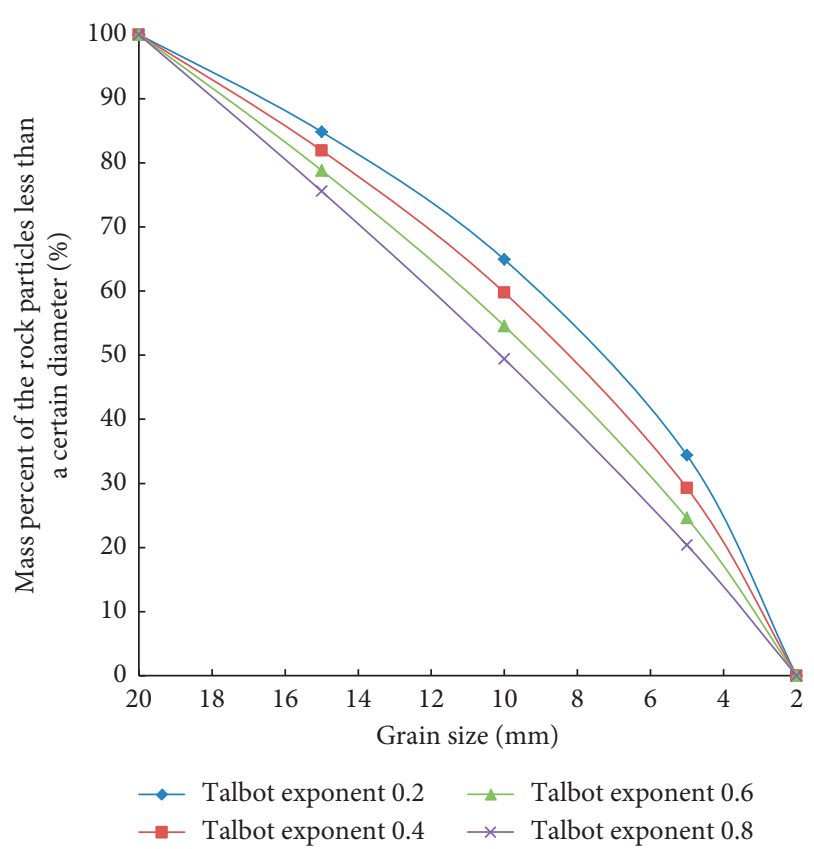

Figure 2: Grain grading curves for four different Talbot exponent.

\section{Calculation of Parameters}

3.1. Compression Modulus. The compression modulus of the saturated crushed gangue is defined by

$$
E_{s}=\frac{\mathrm{d} \sigma_{1}}{\mathrm{~d} \varepsilon}
$$

where $E_{s}$ is the compression modulus, $\sigma_{1}$ is the axial stress, and $\varepsilon$ is the axial strain.

3.2. Relative Breakage. Hardin [24] proposed that the probability of the particle breakage increases with its size. It was also noted that it is difficult for the particles with a size smaller than $0.074 \mathrm{~mm}$ to be broken again. Thus, all particles larger than this size are likely to be broken to different degrees of magnitudes. The potential for breakage, $b_{p}$, of a particle of a given size, $D$, may be represented by

$$
b_{p}= \begin{cases}\log _{10}\left[\frac{D}{0.074}\right], & D \geq 0.074 \mathrm{~mm}, \\ 0, & D<0.074 \mathrm{~mm} .\end{cases}
$$

For the whole specimen, the breakage potential, $B_{p}$, can be expressed by

$$
B_{p}=\int_{0}^{1} b_{p} \mathrm{~d} f
$$

where $\mathrm{d} f$ is the differential of "percent passing" divided by 100 with $b_{p}$.

The total breakage, $B_{t}$, may be represented by

$$
B_{t}=\int_{0}^{1}\left(b_{p 0}-b_{p l}\right) \mathrm{d} f
$$

in which the $b_{p 0}=$ the original values of $b_{p}$; and the $b_{p l}=$ the values of $b_{p}$ after loading starts.

The relative breakage, $B_{r}$, may be represented by

$$
B_{r}=\frac{B_{t}}{B_{p}},
$$

where the value interval of $B_{r}$ is $[0,1]$, which can be used to quantify the overall breakage degree of gangue particles.

3.3. Particle Circularity. In this research, the particle circularity, $e$, was employed to quantify the evolution of particle morphology. It was expressed by the following equation:

$$
e=\frac{L}{2 \sqrt{\pi A}}
$$

where $L$ is the perimeter of the particle projection area, and $A$ is the particle projection area. Based on the definition of 
circularity, the more regular particles result in the smaller circularity values. When particles are spherical, the corresponding circularity value is 1 . In contrast, the more particle angles lead to the larger circularity values.

\section{Test Results}

4.1. Deformation. Based on the test data of axial stress and axial strain, we obtained the relationship between axial strain and axial stress (Figure 3). As observed, the axial strain increased with an increase in axial stress. The increase in axial strain consisted of two stages: the rapid increase (0-4 MPa) stage and the slow increase (4-20 MPa) stage. During the rapid increase stage, the axial strain increased quickly by more than $69 \%$ of the total increase $(0-20 \mathrm{MPa})$.

The axial strain was influenced by the initial gradation. Under the same axial stress, a larger Talbot exponent gave rise to a larger strain. This came mostly from the fact that a larger Talbot exponent corresponded to a greater mass percent of large particles, which was more likely to cause large space in specimen.

The relationship between axial strain and axial stress was fitted by a negative exponential function, and the correlation coefficients were all above 0.99 . The axial strain was expressed using the following relationship:

$$
\varepsilon=a_{1}\left(1-e^{-\sigma_{1} / b_{1}}\right)
$$

where $\varepsilon$ is the axial strain, $\sigma_{1}$ is the axial stress, and $a_{1}$ and $b_{1}$ are fitting parameters.

When the specimen was compressed to a certain degree, the variation of axial strain tended to become 0 (i.e., $\left.\left(\mathrm{d} \varepsilon / \mathrm{d} \sigma_{1}\right) \mid \sigma_{1} \longrightarrow \infty=0\right)$, and there was a limit value for axial strain. From equation (8), it was found that $\varepsilon_{\lim \sigma_{1} \longrightarrow+\infty}=\varepsilon_{l}$, and the axial strain was expressed by

$$
\varepsilon=\varepsilon_{l}\left(1-e^{-\sigma_{1} / b_{1}}\right) \text {. }
$$

From equations (2) and (9), the compression modulus, $E_{s}$, was expressed by

$$
E_{s}=\frac{\mathrm{d} \sigma_{1}}{\mathrm{~d} \varepsilon}=\frac{b_{1}}{\varepsilon_{l}} e^{\sigma_{1} / b_{1}}
$$

When $\sigma_{1}$ was equal to 0 , the compression modulus could be written as $E_{s}^{0}$, and then we obtained the following equation:

$$
E_{s}^{0}=\left.\frac{\mathrm{d} \sigma_{1}}{\mathrm{~d} \varepsilon}\right|_{\sigma_{1}=0}=\frac{b_{1}}{\varepsilon_{l}} .
$$

From equation (11), we obtained the following formula:

$$
b_{1}=\varepsilon_{l} E_{s}^{0}
$$

Based on equations (10) and (12), the relationship between compression modulus and axial stress was expressed by

$$
E_{s}=E_{s}^{0} e^{\sigma_{1} / \varepsilon_{l} E_{s}^{0}}
$$

4.2. Particle Crushing. Table 1 shows the particle size distribution of specimen with $n=0.6$ under compaction, and Figure 4 exhibits the variation trend of gangue particles within each size range. Particle crushing was common in the compaction process and continuously changed the particle size distribution (Figure 4). At the beginning of compaction, before reaching the axial stress of $2 \mathrm{MPa}$, a large number of small particles within the range of $0-2 \mathrm{~mm}$ appeared (Figure $4(\mathrm{a})$ ). This accounted for $42.53 \%$ of the final increment. The large particles in the range of $10-15 \mathrm{~mm}$ also significantly decreased (Figure $4(\mathrm{e})$ ), which accounted for $35.92 \%$ of the final reduction. This originated from the fact that there were a large number of big particles with sharp edges and angles, and the contact between particles was predominantly point to point and point to surface. Hence, these contacts easily led to fracture and breakage. As a result, the particle size changed greatly. When the axial stress exceeded $12 \mathrm{MPa}$, the mass in each size range changed slightly. This was primarily because, after the early stage, the particle shape was relatively regular, the contact between particles was dense, and the particle breakage was largely due to the mutual grinding between large particles, accompanied by a small number of small particles. Also, the mass of particles in the range of 2-5 and 5-10 $\mathrm{mm}$ fluctuated locally during the whole compaction process (see Figures 4(b) and 4(c)). This was because the generation and disappearance of particles within these size ranges were random.

Table 2 exhibits the calculation results of relative breakage, and Figure 5 shows the relative breakage vs. axial stress curves. As indicated in Figure 5, the relative breakage changed from 0 to 0.3685 and increased monotonously with the increase of the axial stress. When the axial stress was less than $2 \mathrm{MPa}$, the relative breakage increased promptly. This accounted for $39.15 \%$ to $47.46 \%$ of the total increment. The relative breakage increased slowly between $2 \mathrm{MPa}$ and $12 \mathrm{MPa}$ and tended to become stable after $12 \mathrm{MPa}$. Besides, the initial particle size distribution had little impact on the relative breakage.

4.3. Morphology Evolution. The measure function of ImageJ was employed in this research to calculate the area and perimeter of each particle. Then, the circularity of each particle was calculated using equation (7). Figure 6 illustrates the image processing.

Figure 7 shows the relationship between particle circularity and axial stress. As seen, the particle circularity varied from 1.179 to 1.361 . With the increase of axial stress, the particles circularity decreased gradually. This was mainly because, during compaction, particle breakage occurred constantly, and particle edges and corners fall off. Hence, the particle became more and more regular. Moreover, the circularity of large particles decreased more significantly, especially in the early stage of compaction. For example, under the axial stress of $2 \mathrm{MPa}$, the reduction of large particles in the range of $15-20 \mathrm{~mm}$ accounted for $48.34 \%$ to $52.70 \%$ of the final decrement. This was chiefly because large particles had many edges and corners before compaction, and the stress concentration was easy to occur. 


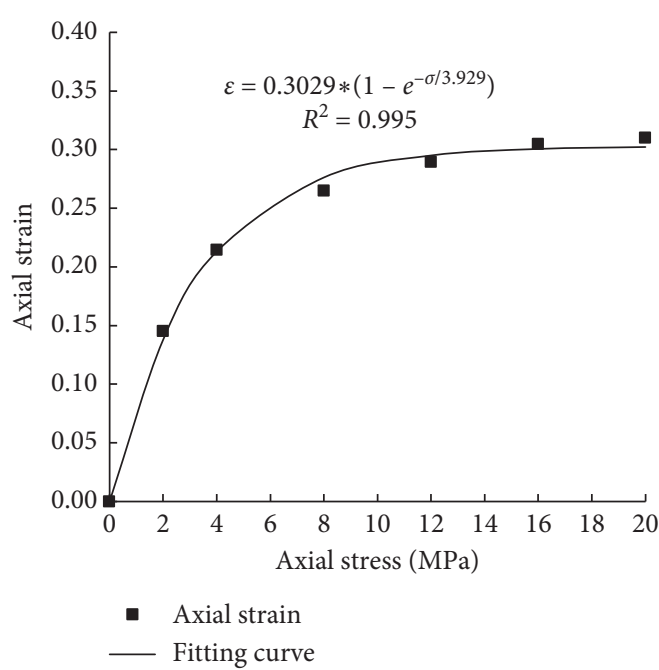

(a)

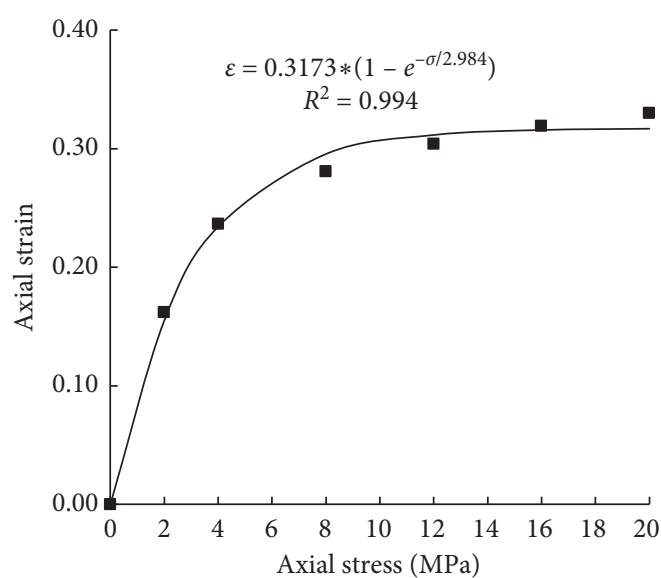

- Axial strain

- Fitting curve

(c)

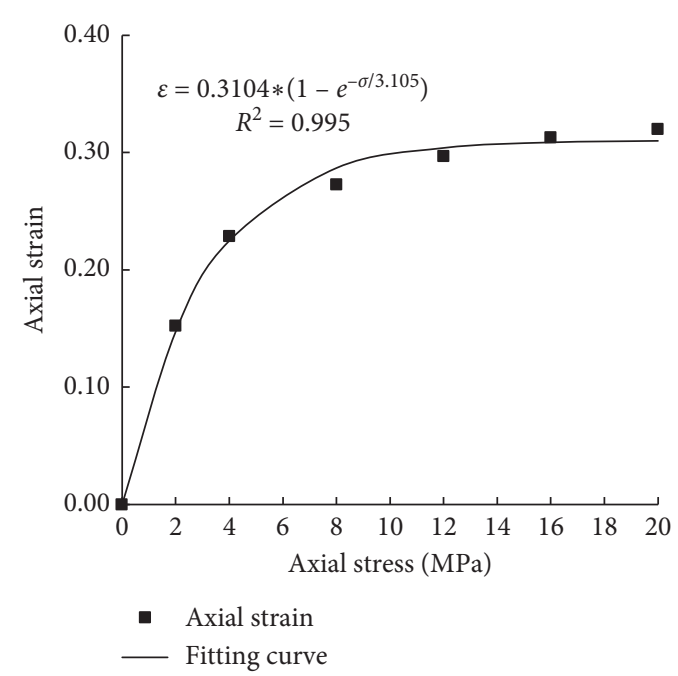

(b)

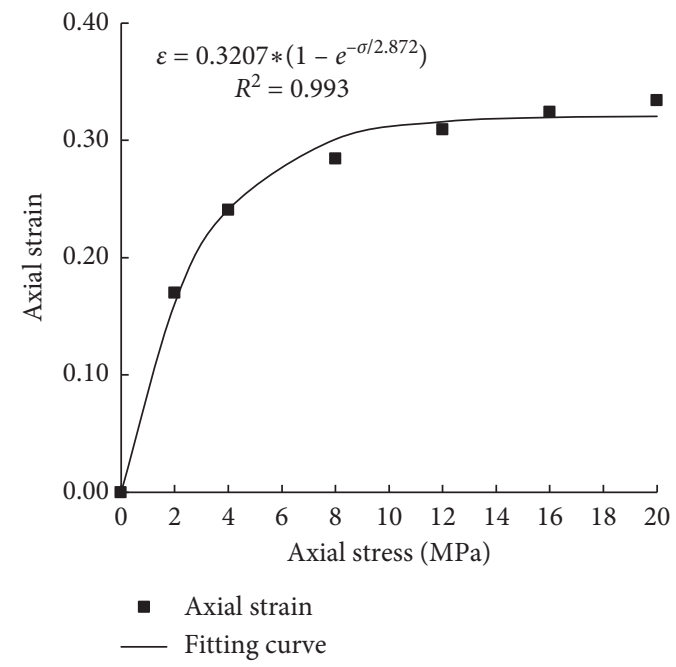

(d)

Figure 3: Axial strain vs. axial stress curves: (a) $n=0.2$; (b) $n=0.4$; (c) $n=0.6$; (d) $n=0.8$.

TABLe 1: Particle size distribution of specimen under compaction $(n=0.6)$.

\begin{tabular}{lccccc}
\hline $\begin{array}{l}\text { Axial } \\
\text { stress } \\
(\mathrm{MPa})\end{array}$ & $0-2 \mathrm{~mm}$ & $2-5 \mathrm{~mm}$ & $5-10 \mathrm{~mm}$ & $10-15 \mathrm{~mm}$ & $15-20 \mathrm{~mm}$ \\
\hline $\begin{array}{l}\text { Initial } \\
\text { state }\end{array}$ & 0 & 24.59 & 29.98 & 24.27 & 21.17 \\
2 & 12.50 & 21.18 & 27.32 & 22.63 & 16.37 \\
4 & 18.10 & 22.50 & 25.84 & 21.24 & 12.32 \\
8 & 22.73 & 21.04 & 26.93 & 18.72 & 10.59 \\
12 & 24.17 & 22.39 & 28.36 & 15.01 & 10.06 \\
16 & 25.92 & 24.69 & 26.45 & 14.49 & 8.45 \\
20 & 29.40 & 24.35 & 25.17 & 13.27 & 7.81 \\
\hline
\end{tabular}

\section{Discussion}

Figure $8(\mathrm{a})-8$ (c) show the arrangement of particles under the axial stress of $2 \mathrm{MPa}, 4 \mathrm{MPa}$, and $8 \mathrm{MPa}$, respectively. At the early stage of compaction (2 MPa), shown in Figure $8(\mathrm{a})$, the specimen was very loose due to the presence of few contact points between particles and the large pore size. The particles accumulated together chaotically and made contact with each other in the form of point-to-point and point-tosurface. After the axial load was applied, particles were moved and rearranged, and the mode of contact was gradually transformed to surface-to-surface contact, which was a stable situation. In particular, when the axial stress was equal to $8 \mathrm{MPa}$, shown in Figure 8(c), the number and size of pores diminished significantly, and the connectivity between pores became poor. Moreover, during the compaction, large pores were primarily distributed around large particles. This indicated that large particles were more likely to cause large pore space.

Particle crushing was mainly divided into three types: fracture, crushing, and grinding (Figure 9) [25]. When there were defects in the gangue particles, they were often divided into heterogeneous particles (Figure 9(a)). When gangue particles had more angular features, point contact was 


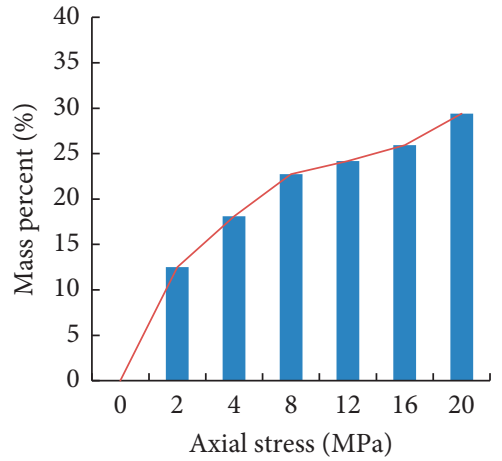

(a)

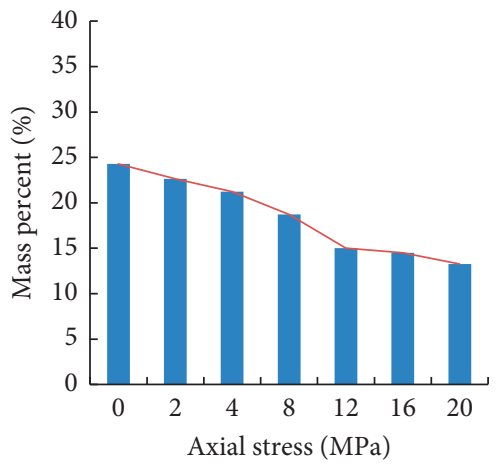

(d)

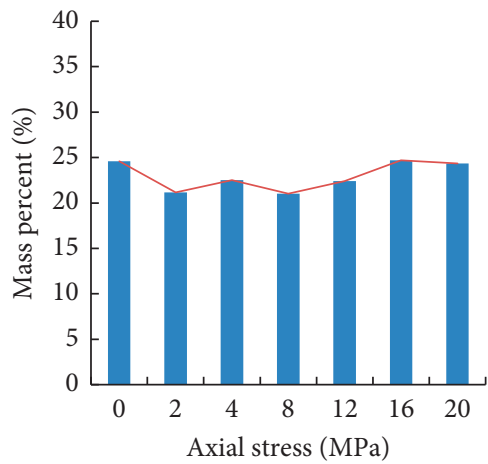

(b)

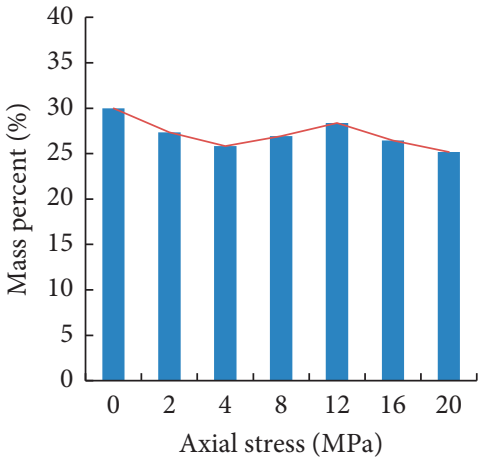

(c)

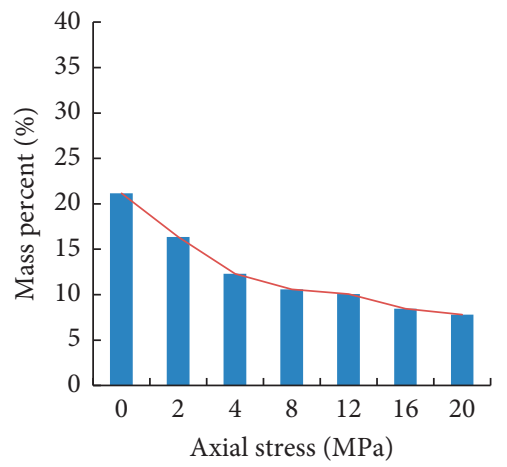

(e)

Figure 4: Mass percent of the rock particles in each diameter size under compaction $(n=0.6)$. (a) $0-2 \mathrm{~mm}$. (b) 2-5 mm. (c) 5-10 mm. (d) $10-15 \mathrm{~mm}$. (e) $15-20 \mathrm{~mm}$.

TABLE 2: Relative breakage of specimens under compaction.

\begin{tabular}{|c|c|c|c|c|c|c|c|}
\hline \multirow{2}{*}{ Talbot exponent } & \multicolumn{7}{|c|}{ Relative breakage } \\
\hline & Initial state & $2 \mathrm{MPa}$ & $4 \mathrm{MPa}$ & $8 \mathrm{MPa}$ & $12 \mathrm{MPa}$ & $16 \mathrm{MPa}$ & $20 \mathrm{MPa}$ \\
\hline 0.2 & 0 & 0.1395 & 0.1931 & 0.2526 & 0.2904 & 0.3024 & 0.3264 \\
\hline 0.4 & 0 & 0.1454 & 0.1957 & 0.2163 & 0.3128 & 0.3499 & 0.3552 \\
\hline 0.6 & 0 & 0.1563 & 0.2172 & 0.2725 & 0.3232 & 0.3320 & 0.3465 \\
\hline 0.8 & 0 & 0.1749 & 0.2440 & 0.2913 & 0.3463 & 0.3630 & 0.3685 \\
\hline
\end{tabular}

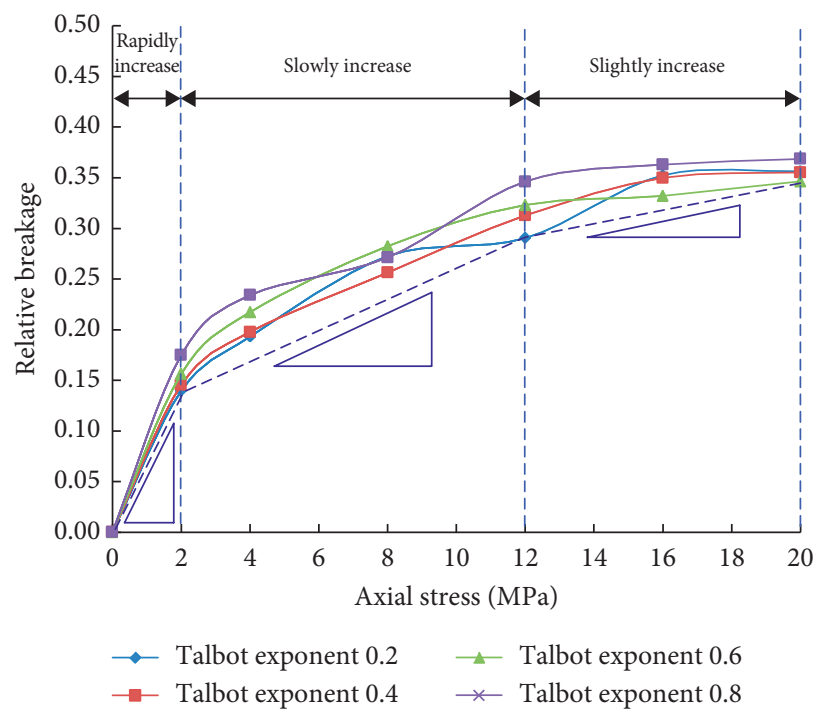

Figure 5: The relationship between the relative breakage and axial stress. 


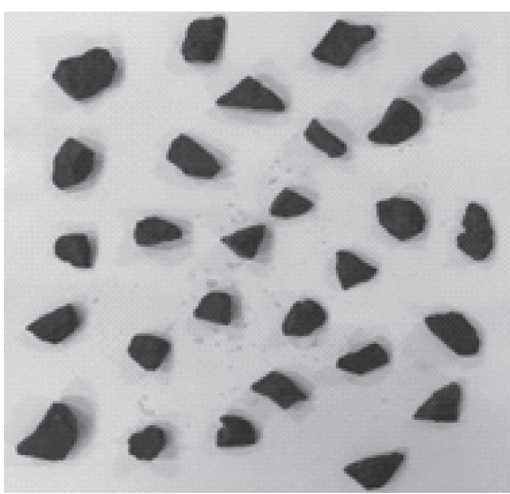

(a)

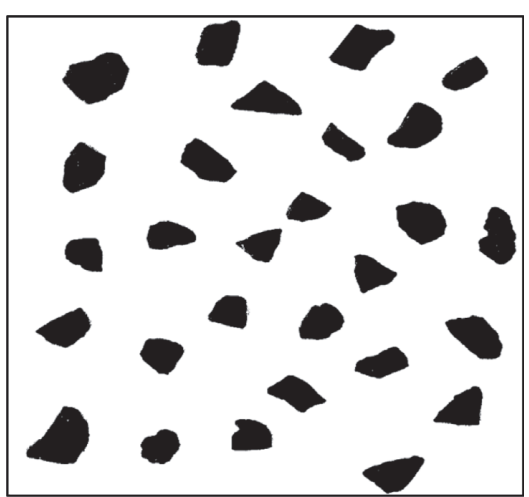

(b)

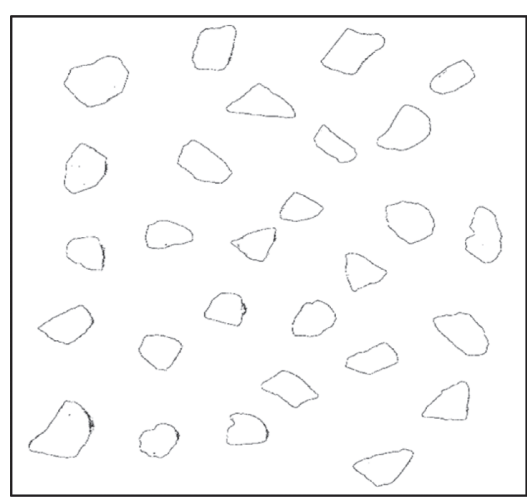

(c)

FIguRE 6: Image processing: (a) Digital image. (b) Binary image. (c) Particles contours.

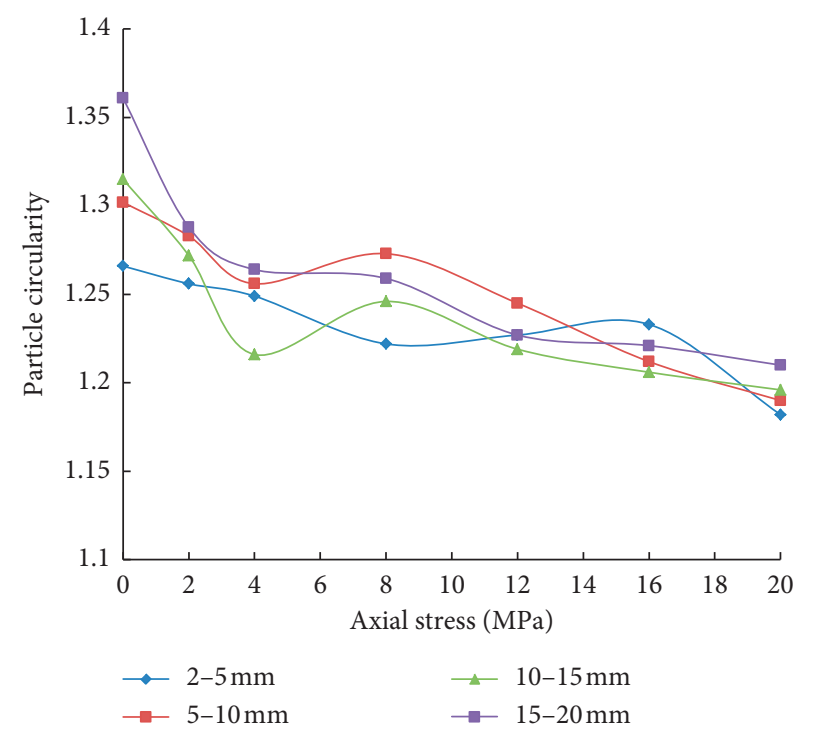

(a)

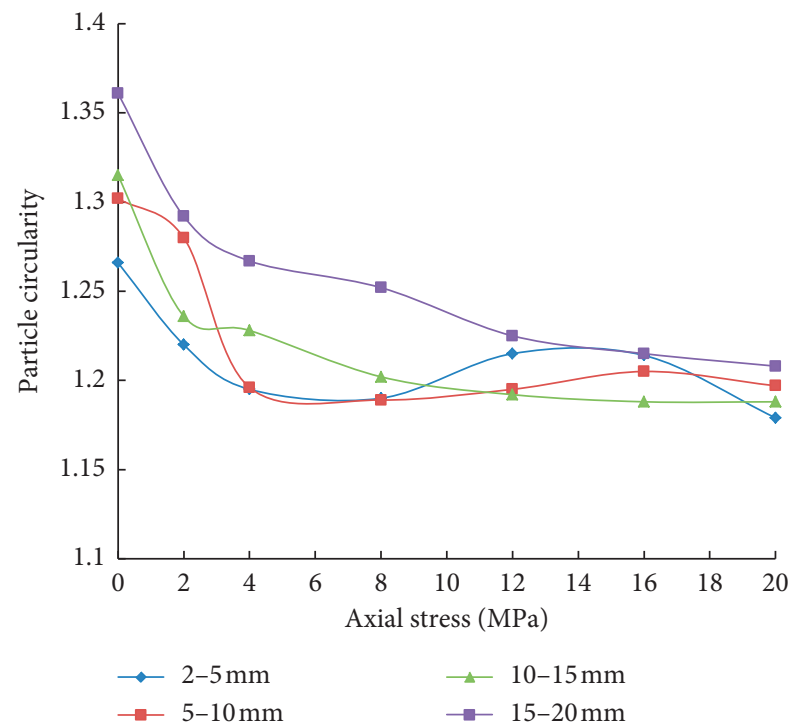

(c)

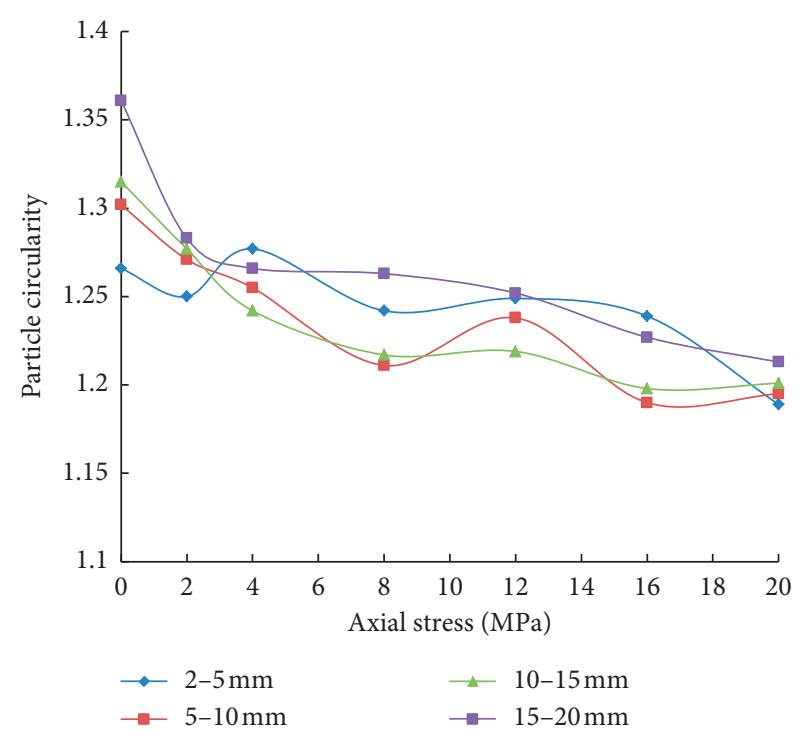

(b)

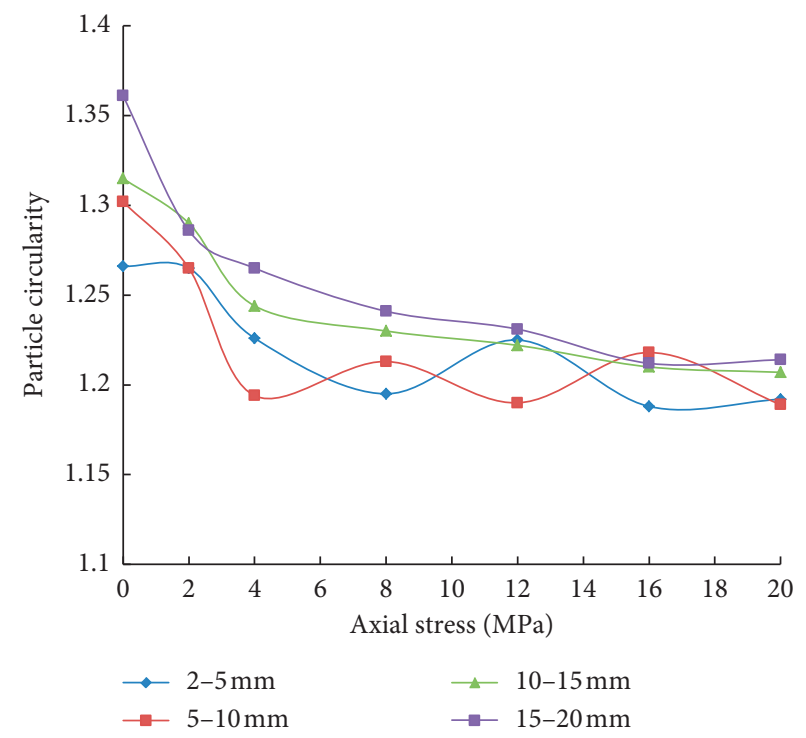

(d)

FIGURE 7: The relationship between circularity and axial stress: (a) $n=0.2$; (b) $n=0.4$; (c) $n=0.6$; (d) $n=0.8$. 


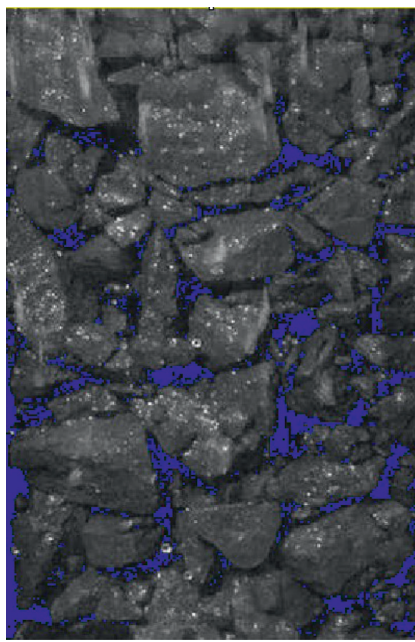

(a)

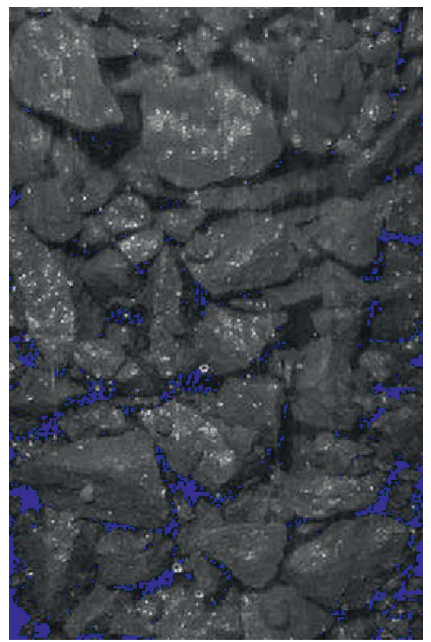

(b)

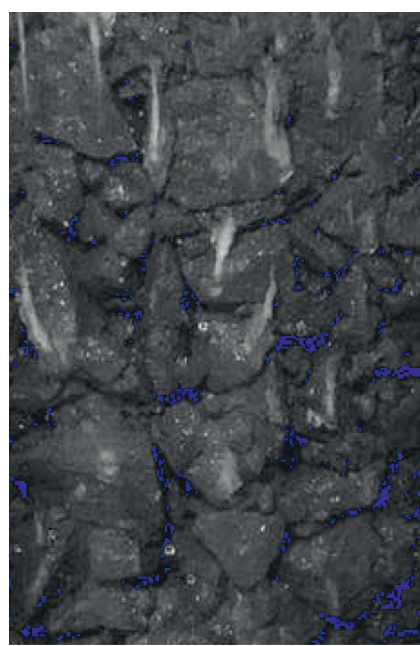

(c)

Figure 8: Arrangement of particles under compaction: (a) $2 \mathrm{MPa}$; (b) $4 \mathrm{MPa}$; (c) $8 \mathrm{MPa}$.
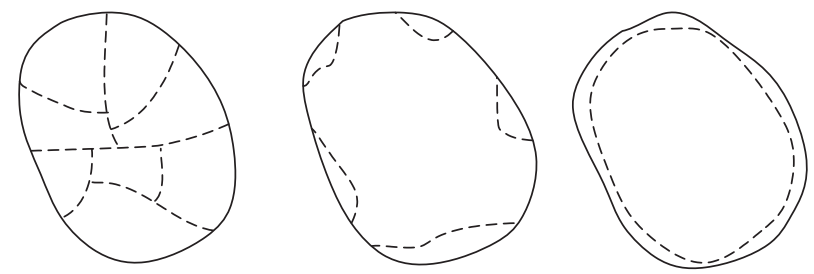

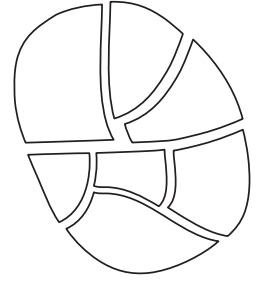

(a)

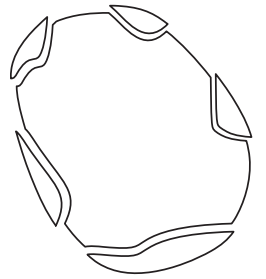

(b)

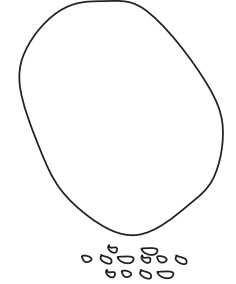

(c)

FIGURE 9: Three types of rock particles crushing: (a) Fracture. (b) Crushing. (c) Grinding.

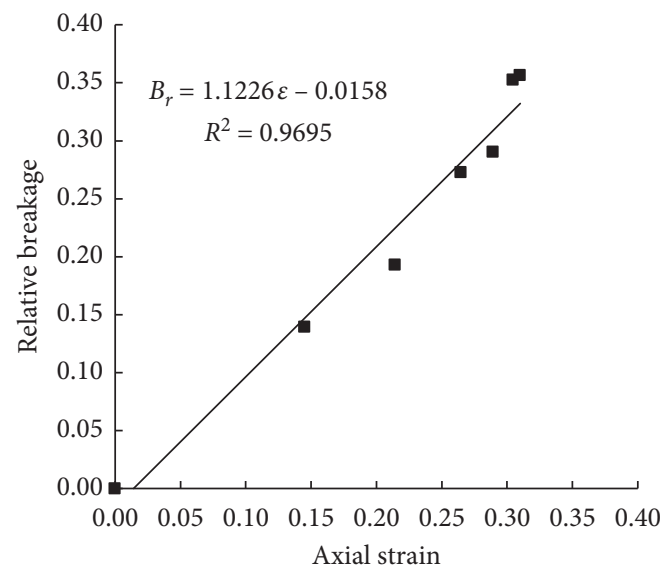

(a)

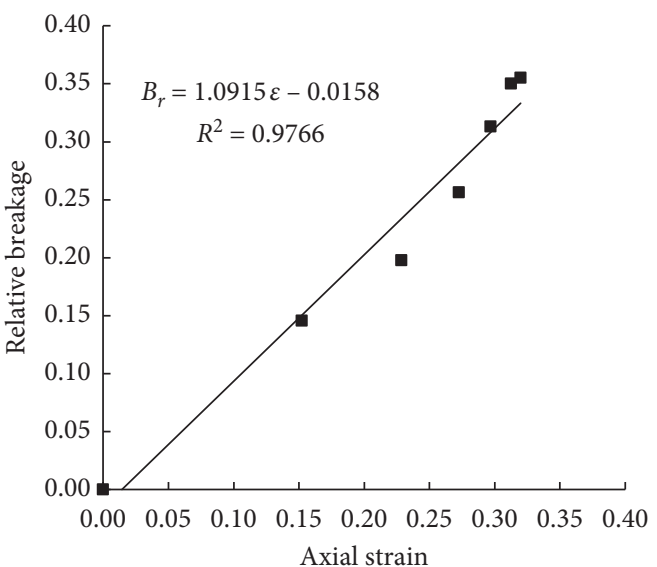

(b)

Figure 10: Continued. 


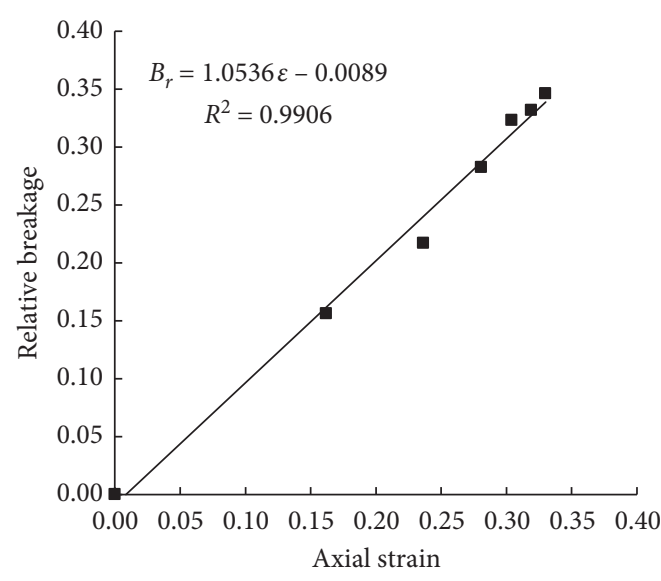

(c)

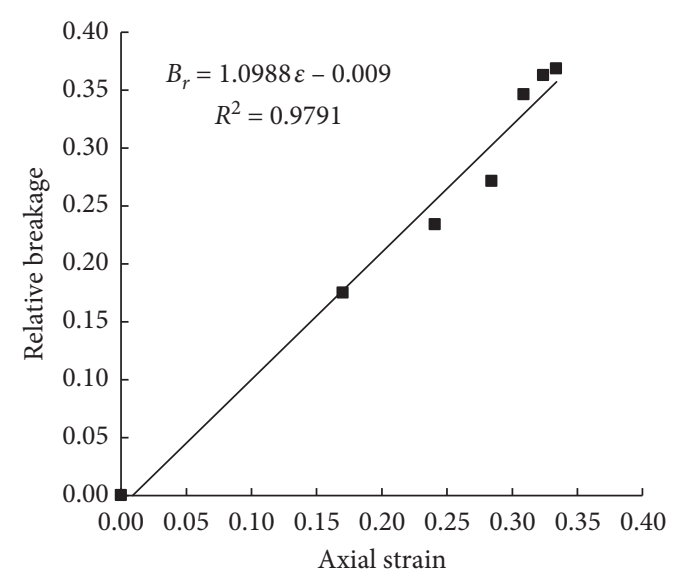

(d)

FIgURE 10: The linear curves between relative breakage and axial strain: (a) $n=0.2$; (b) $n=0.4$; (c) $n=0.6$; (d) $n=0.8$.

formed between the particles, which often resulted in stress concentration and angular shedding (Figure 9(b)). When gangue particles had regular contour and low surface roughness, mutual grinding between the particles often occurred. This made the sample shape more regular and the surface smoother (Figure 9(c)). At the early stage of compaction, fracture and crushing occurred in large numbers, which resulted in a rapid increase of relative breakage and a swift reduction of particle circularity, respectively. At the later stage of compaction, grinding was the main form of particle crushing, which led to a slow increase of relative breakage and a slow reduction of particle circularity.

The main reasons for the compression of saturated crushed gangue were as follows: (1) Under the action of the axial loading, gangue particles overcame the frictional resistance between particles. This resulted in sliding and rolling to a more stable position; hence, it led to a reduction in the void volume. (2) Gangue particles were broken. Thus, the gaps between large particles were filled with small particles, resulting in the volume reduction.

Figure 10 shows the relative breakage vs. axial strain curves. It can be observed that the relative breakage increased with an increase in the axial strain. That was mainly because, with the increase of axial strain, the degree of particle breakage became more serious. Moreover, the relationship between the relative breakage and axial strain was described by a linear function as follows:

$$
B_{r}=a_{2} \varepsilon+b_{2},
$$

where $a_{2}$ and $b_{2}$ are the regression coefficients.

\section{Conclusion}

In this research, the deformation, particle crushing, and morphology evolution of saturated crushed gangue were investigated by performing a series of laboratory tests with our self-designed compacting device. Through the above study, the following conclusions were drawn:

(1) The axial strain increased with an increase in axial stress. This increase consisted of two stages: the rapid increase $(0-4 \mathrm{MPa})$ stage and the slow increase (4-20 MPa) stage. The axial strain was influenced by the initial gradation. Under the same axial stress, a larger Talbot exponent corresponded to a larger strain. The relationship between compression modulus and axial stress was expressed by an exponential function.

(2) Particle crushing was common in the compaction process and continuously changed the particle size distribution. The relative breakage varied from 0 to 0.3685 and increased monotonously with the increase of axial stress. This increase consisted of three stages: the rapid increase $(0-2 \mathrm{MPa})$, the slow increase $(2-12 \mathrm{MPa})$, and the slight increase $(12-20 \mathrm{MPa})$. During the rapid increase stage, the relative breakage increased rapidly by more than $39.15 \%$ of the total increment $(0-20 \mathrm{MPa})$. The initial gradation had little impact on the relative breakage.

(3) The particle circularity varied from 1.179 to 1.361. With the increase of axial stress, the particles circularity reduced gradually. The circularity of large particles reduced more significantly. At the early stage of compaction $(0-2 \mathrm{MPa})$, the circularity of large particles in the range of $15-20 \mathrm{~mm}$ diminished by more than $48.34 \%$ of the total decrement.

(4) Particle crushing was predominantly divided into three types: fracture, crushing, and grinding. At the early stage of compaction, fracture and crushing took place in large numbers. At the end of the compaction, grinding was the main form of particle crushing.

(5) The relative breakage increased with an increase in the axial strain. The relationship between these two was described by a linear function.

\section{Data Availability}

The article data used to support the findings of this study are included within the article. 


\section{Conflicts of Interest}

The authors declare that there are no conflicts of interest regarding the publication of this paper.

\section{Acknowledgments}

This work was supported by the Science and Technology Project of Changzhou (Grant no. CJ20190020), the Natural Science Foundation of the Jiangsu Higher Education Institutions of China (Grant no. 18KJB440002), and the Science and Technology Project of Housing and Construction in Jiangsu Province (Grant no. 2018ZD199).

\section{References}

[1] S. Peng, Longwall Mining, West Virginia University, Morgantown, CO, USA, 2006.

[2] X. Miao, S. Li, Z. Chen, and W. Liu, "Experimental study of seepage properties of broken sandstone under different porosities," Transport in Porous Media, vol. 86, no. 3, pp. 805-814, 2011.

[3] D. Ma, H. Bai, Z. Chen, and H. Pu, "Effect of particle mixture on seepage properties of crushed mudstones," Transport in Porous Media, vol. 108, no. 2, pp. 257-277, 2015.

[4] G. R. McDowell and J. J. Khan, "Creep of granular materials," Granular Matter, vol. 5, no. 3, pp. 115-120, 2003.

[5] S. L. Karner, J. S. Chester, F. M. Chester, A. K. Hajash, and A. K. Kronenberg, "Laboratory deformation of granular quartz sand: implications for the burial of clastic rocks," AAPG Bulletin, vol. 89, no. 5, pp. 603-625, 2005.

[6] R. H. Brzesowsky, S. J. T. Hangx, N. Brantut, and C. J. Spiers, "Compaction creep of sands due to time-dependent grain failure: effects of chemical environment, applied stress, and grain size," Journal of Geophysical Research: Solid Earth, vol. 119, no. 10, pp. 7521-7541, 2014.

[7] Z. Ma, R. Gu, Z. Huang, G. Peng, L. Zhang, and D. Ma, "Experimental study on creep behavior of saturated disaggregated sandstone," International Journal of Rock Mechanics and Mining Sciences, vol. 66, no. 1, pp. 76-83, 2014.

[8] N. Miura and S. O-Hara, "Particle-crushing of a decomposed granite soil under shear stresses," Soils and Foundations, vol. 19, no. 3, pp. 1-14, 1979.

[9] E. Perfect, "Fractal models for the fragmentation of rocks and soils: a review," Engineering Geology, vol. 48, no. 3-4, pp. 185-198, 1997.

[10] K. Li and R. N. Horne, "Experimental study and fractal analysis of heterogeneity in naturally fractured rocks," Transport in Porous Media, vol. 78, no. 2, pp. 217-231, 2009.

[11] R. R. Filgureira, L. L. Fournier, C. I. Cerisola, P. Gelati, and M. G. García, "Particle-size distribution in soils: a critical study of the fractal model validation," Geoderma, vol. 134, no. 3-4, pp. 327-334, 2006.

[12] Y. Chen, B. Yu, K. Zhang, M. Zhang, G. Xu, and Z. Chen, "Permeability evolution and particle size distribution of saturated crushed sandstone under compression," Geofluids, vol. 2018, Article ID 6043420, 12 pages, 2018.

[13] J. Zheng and R. D. Hryciw, "Traditional soil particle sphericity, roundness and surface roughness by computational geometry," Géotechnique, vol. 65, no. 6, pp. 494-506, 2015.

[14] K. A. Alshibli, A. M. Druckrey, and R. I. Al-Raoush, "Quantifying morphology of sands using 3D imaging," Journal of Materials in Civil Engineering, vol. 27, no. 10, 2015.
[15] K. S. Shah, M. H. B. M. Hashim, M. Z. Emad, K. S. B. Ariffin, M. Junaid, and N. M. Khan, "Effect of particle morphology on mechanical behavior of rock mass," Arabian Journal of Geoences, vol. 13, no. 15, p. 708, 2020.

[16] W. Zhou, K. Xu, L. F. Yang, and G. Ma, "Influence of particle shape on mechanical behavior of granular materials," in Proceedings of the 7th International Conference on Discrete Element Methods, pp. 245-252, Dalian, China, August 2016.

[17] F. D Cola, A. Pellegrino, C. Glößner, D. Penumadu, and N. Petrinic, "Effect of particle morphology, compaction, and confinement on the high strain rate behavior of sand," Experimental Mechanics, vol. 58, no. 2, pp. 223-242, 2018.

[18] G.-C. Cho, J. Dodds, and J. C. Santamarina, "Particle shape effects on packing density, stiffness, and strength: natural and crushed sands," Journal of Geotechnical and Geoenvironmental Engineering, vol. 132, no. 5, pp. 591-602, 2006.

[19] J.-J. Wang, Y.-Z. Cheng, H.-P. Zhang, and D.-P. Deng, "Effects of particle size on compaction behavior and particle crushing of crushed sandstone-mudstone particle mixture," Environmental Earth Sciences, vol. 73, no. 12, pp. 8053-8059, 2015.

[20] Z. G. Ma, G. L. Guang, R. H. Chen, and X. B. Mao, “An experimental study on the compaction of water-saturated over-broken rock," Chinese Journal of Rock Mechanics and Engineering, vol. 24, no. 7, pp. 1139-1144, 2005.

[21] Z. Q. Chen, S. C. Li, X. B. Mao, and X. W. Huang, "Experiment on the porosity changing of water-saturated granular limestone during its creep," Journal of China Coal Society, vol. 31, no. 1, pp. 26-30, 2006.

[22] Z. L. Cheng and H. S. Ding, "Creep test for rockfill," Chinese Journal of Geotechnical Engineering, vol. 26, no. 4, pp. 473477, 2004.

[23] B. Yu, Z. Chen, and J. Wu, "Experimental investigation on seepage stability of filling material of karst collapse pillar in mining engineering," Advances in Civil Engineering, vol. 2018, Article ID 3986490, 10 pages, 2018.

[24] B. O. Hardin, "Crushing of soil particles," Journal of Geotechnical Engineering, vol. 111, no. 10, pp. 1177-1192, 1985.

[25] E. Guyon and J. P. Troadec, Du sac de billes au tas de asble, Odile Jacob Science, Paris, France, 1994. 